\title{
MEDIAÇÃO E CONCILIAÇÃO: reflexões à luz do novo Código de Processo Civil
}

\author{
Vera Leticia de Oliveira Silva ${ }^{1}$
}

RESUMO

O artigo tece reflexões sobre a mediação e a conciliação à luz do novo Código de Processo Civil, que entrou em vigor em março de 2016. Analisa-se a incapacidade do Judiciário solucionar os problemas reais das pessoas, além de demonstrar que um dos caminhos para superar este obstáculo é a utilização de meios alternativos de pacificação de conflitos. Nestas vias autônomas de composição de conflitos as partes possuem voz ativa e são as protagonistas das decisões. Serão aqui analisados os institutos da mediação e da conciliação e como são eles tratados no novo diploma processual, traçando algumas ponderações positivas e outras que indicam a necessidade de uma reflexão sobre a utilidade e eficácia dos novos preceitos legais.

Palavras-chave: Mediação. Conciliação. Novo Código de Processo Civil.

\section{INTRODUÇÃO}

A busca pelo Acesso à Justiça tem mostrado caminhos promissores, dentre ao quais merece destaque a utilização de meios alternativos de pacificação de conflitos, como a conciliação e mediação (CAPPELLETTI, 1998), inclusive, dentro do próprio processo judicial. O Código de Processo Civil de 1973(CPC/73) previa, por exemplo, a conciliação como um passo fundamental no processo de rito sumário, igualmente prevendo, desde a Lei 8.052/94 (que alterou o art. 331 do CPC), obrigatória audiência de conciliação também no procedimento ordinário de conhecimento.

Busca-se, neste artigo tecer reflexões sobre a mediação e a conciliação à luz do novo Código de Processo Civil (CPC/15), que recentemente entrou em vigor.

O Conselho Nacional de Justiça (CNJ), através da Resolução n ${ }^{\circ} 125$ de 2010, já se mostrou partidário da ideia de utilização de meios autônomos de composição de conflitos. No entanto, apesar dos esforços e da grande relevância que estes mecanismos

\footnotetext{
${ }^{1}$ Graduanda em Direito pela Universidade Estadual de Feira de Santana. Bolsista pela FAPESB da Incubadora de Iniciativas da Economia Popular e Solidária da UEFS. Integrante do Grupo de Estudos e Pesquisas em Economia Popular e Solidária (GEPOSDEL). Estagiária do escritório Cajado de Menezes Advogados E-mail: veraleticiaoliveira@gmail.com.
} 
possuem, ainda carecem do devido reconhecimento, em especial por parte dos magistrados e dos advogados, que relutam em adotar tais práticas perpetuando a cultura do litígio.

A pesquisa e a prática forense têm demonstrado que o Poder Judiciário, tal como se apresenta, tem se tornado por vezes incapaz de resolver os problemas reais das pessoas. Essa incapacidade se deve a uma série de fatores, dentre os quais se podem destacar o grande volume de processos, a morosidade e o alto custo de uma demanda judicial. Atrelado a estes problemas tem-se ainda o fato de que um conflito ao ser levado ao Judiciário converte-se em um conflito jurídico, ao qual será dado um tratamento "padronizado", similar a todos os demais, supondo-se que ele se "resolverá" com uma sentença. No entanto, sabe-se que o conflito social, de regra, ainda persistirá e tenderá a comprometer a eficácia da decisão judicial.

É visando romper com estes problemas e criar caminhos para o acesso à justiça que o legislador trouxe os meios autocompositivos como institutos norteadores do novo Código de Processo Civil. Sendo possível observar, já no artigo $3^{\circ}, \S 3^{\circ 2}$ do novo CPC, que se dará preferência aos meios alternativos de pacificação de controvérsias ao invés da instauração do processo judicial.

Observa-se também a importância dos meios de autocomposição no novo Código quando o legislador torna obrigatória a audiência de mediação e conciliação antes mesmo da apresentação de defesa do réu (artigo 334 e parágrafos).

Destaca-se ainda o cuidado do legislador em diferenciar a mediação da conciliação e possibilitar que seja adotada a melhor metodologia para cada conflito. Alguns doutrinadores, a exemplo de Josiane Rigon (apud TRENTIN, 2013), entendem que a mediação é mais apropriada para discutir questões que envolvem conflitos de família, vizinhança e demais relações duradouras que já existiam antes do conflito e continuarão a existir depois dele, ao passo que a conciliação seria mais indicadas nas questões da área comercial e de consumo, onde o vínculo entre as partes é passageiro e se deve, em geral, a relações jurídicas temporárias. No entanto, Adolfo Braga Neto, entende ser possível utilizar da mediação "em quase todos os conflitos entre pessoas físicas" no âmbito familiar, na seara cível, comercial, trabalhistas e ainda em "conflitos

\footnotetext{
${ }^{2}$. Art. $3^{\circ}$ Não se excluirá da apreciação jurisdicional ameaça ou lesão a direito.

[...]

$\S 3^{\circ} \mathrm{A}$ conciliação, a mediação e outros métodos de solução consensual de conflitos deverão ser estimulados por juízes, advogados, defensores públicos e membros do Ministério Público, inclusive no curso do processo judicial.
} 
gerados por acidentes de trabalhos" (BRAGA NETO, 1999, p. 95). O novo CPC, apesar de não colocar o fator distintivo como condição sine qua non, adota a primeira corrente, indicando que:

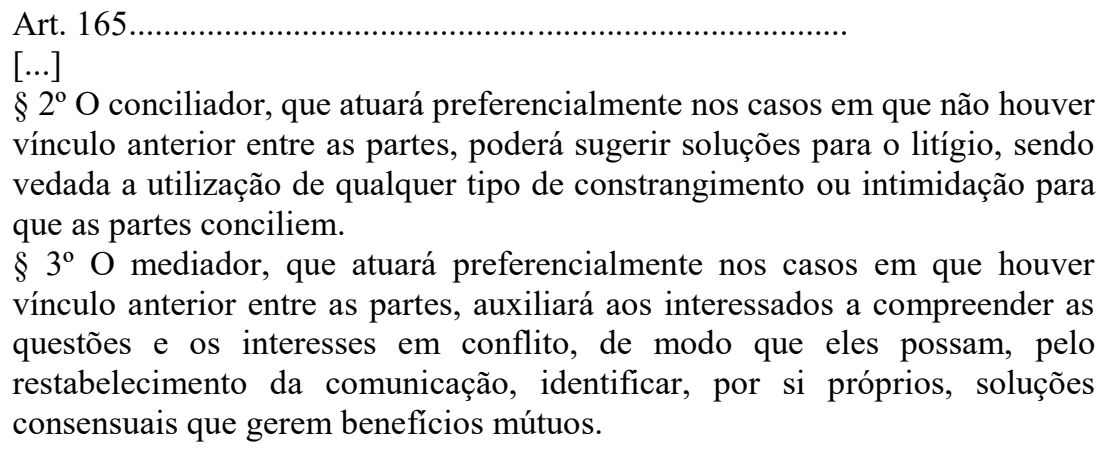

Entretanto, é preciso problematizar várias outras questões que orbitam o tema no novo código. Isto porque, para que estes caminhos alternativos efetivamente funcionem é preciso que os Tribunais promovam uma série de mudanças e adaptações estruturais e humanas, como a criação em todas as comarcas de um Centro de mediação/conciliação e a contratação e formação de novos conciliadores e mediadores.

Por fim, destaca-se o fato de que nos métodos extrajudiciais de pacificação de conflitos as partes ligantes são protagonistas da busca por uma resposta ao conflito, possuindo voz ativa e refletindo sobre a convivência abalada. Importante sublinhar, ainda, que os meios de autocomposição de conflitos são encarados aqui como métodos de pacificação (e não de solução) de controvérsias. Isso porque, entende-se como primordial o reestabelecimento do diálogo e conservação da relação harmoniosa através da análise do conflito e da extração de seu potencial construtivo, no lugar da simples solução da contenda sem se preocupar com os sujeitos em conflito.

\section{METODOLOGIA}

As reflexões aqui apresentadas são resultados de pesquisa teórica que busca investigar os meios alternativos de pacificação de conflitos e a forma com a qual são tratados no Código de Processo Civil de 2015.

Para elaboração deste estudo foi realizada análise do texto legal, verificando o modo como a mediação e a conciliação são concebidas e a forma como serão utilizadas a partir da entrada em vigor do novo Código. O estudo do texto legal foi aliado à leitura 
da doutrina - que tem se mostrado esperançosa com as novas disposições legais possibilitando esboçar algumas reflexões sobre o tema.

Tais reflexões fazem parte do estudo que vem sendo realizado enquanto proposta de iniciação científica na Incubadora de Iniciativas da Economia Popular e Solidária (IEPS-UEFS). A pesquisa original apresenta caráter empírico, que parte de uma análise de reconhecimento da situação-problema, produção de conhecimento técnico passível de aplicação no problema em questão e, paralelamente, projeta e propõe possíveis soluções, interpretando e avaliando os resultados a fim de vislumbrar uma mudança adequada da prática.

O presente estudo é parte do resultado da pesquisa teórica até então desenvolvida sobre os meios de pacificação de conflitos, em especial da mediação e conciliação, que já possibilitou a percepção de sua importância, bem como a necessidade de uma mudança de perspectiva na forma de lidar com o conflito, encarando-o como humano (e não jurídico).

\section{O JUDICIÁRIO E A BUSCA PELO ACESSO À JUSTIÇA}

O Poder Judiciário brasileiro enfrenta uma série de problemas que o torna, por vezes, incapaz de solucionar satisfatoriamente os conflitos que lhes são apresentados. Questões como a superlotação do Judiciário e a falta de recursos humanos e materiais têm tornado o processo judicial longo em demasiado e com decisões cada vez mais distantes da realidade.

No processo judicial, as condições psíquicas e morais das partes, além das tramas pessoais, não são observados pelo sistema que mal escuta os problemas reais das pessoas, preocupando-se quase que somente em traduzir as questões fáticas em questões de direito.

Rebouças afirma que o conflito, quando levado ao "mundo jurídico, na moldura kelseniana, não se faz sem uma dose substancial de mutilação. O que pode ser resolvido não é o conflito, não é a carência em seu estado de resistência. O que pode ser resolvido é somente o conflito jurídico" (2012, p. 142). Em outras palavras, os problemas reais enfrentados pelas pessoas quando chegam ao Judiciário são transformados em problemas jurídicos e será estritamente sobre a questão jurídica que irá incidir a decisão judicial - o que, em regra, não soluciona concretamente os problemas dos litigantes, sendo apenas uma solução imposta de cima para baixo, que pouco, ou nunca, se importa 
em reestabelecer o diálogo entre as partes e tampouco a relação harmoniosa que havia antes do conflito.

O que se resolve, então, não é aquele conflito, mas um conflito qualquer, cuja moldura foi aproveitada de outros conflitos e servirá para tantos outros mais. Desse modo, resta um direito inacessível para grande parte dos sujeitos e os conflitos permanecem apesar da solução distante da realidade (REBOUÇAS, 2012).

Nessas condições, as partes, que agora nada mais são do que figurantes de seus próprios dilemas, são levadas a se enfrentarem, formando polos opostos da relação processual adversarial.

Nesse sentido, oportuna a reflexão de Carlos Maria Cárcova (1988), de que o acesso ao Judiciário é, de regra, estranho à sociedade, porque existe entre o Direito e os seus destinatários uma barreira opaca, que impede a sua perfeita compreensão e acessibilidade. A "opacidade do direito" traduz um conjunto de combinações que perpassam desde a linguagem inacessível e demasiadamente rebuscada (palavras que só existem no mundo jurídico ou que nele tem um significado diferente), às vestes que impõe superioridade, até os rostos e prédios frios e que demonstram desprezo e angústia, mostrando que esse é um universo "para poucos".

A morosidade da justiça provoca um dano intangível às partes processuais. Os processos judiciais demoram anos a fio sem que se obtenha um termo final. O conflito também perdura durante todo este período, o que só aumenta o caráter "litigante" do processo, e, muitas vezes, o próprio bem da vida buscado perde-se ao longo de todos estes anos.

A busca pelo acesso à justiça faz-se, portanto, imprescindível. Mauro Cappelletti e Bryant Garth (1998) indicam que um dos caminhos para se alcançar uma justiça acessível a todos e que de fato produza resultados justos, é a utilização de meios alternativos de pacificação de conflitos.

\footnotetext{
Devemos estar conscientes de nossa responsabilidade; é nosso dever contribuir para fazer que o direito e os remédios legais reflitam as necessidades, problemas e aspirações atuais da sociedade civil; entre essas necessidades estão seguramente as de desenvolver alternativas aos métodos e remédios, tradicionais, sempre que sejam demasiado caros, lentos e inacessíveis ao povo; daí o dever de encontrar alternativas capazes de melhor atender às urgentes demandas de um tempo de transformações sociais em ritmo de velocidade sem precedente. (CAPPELLETTI, 1994, p. 97).
} 
O movimento de acesso à justiça busca superar os obstáculos que impedem certos segmentos de obter efetiva prestação jurisdicional. Cappelletti e Garth problematizam a conjuntura dos mecanismos e instituições, pessoas e procedimentos processuais como obstáculo processual ao acesso à justiça. Desta forma, no que chamaram de "terceira onda" de acesso à justiça, são exploradas as alternativas de pacificação de conflitos (1994).

Por outro lado, os mecanismos de autocomposição, como veremos a diante, concedem autonomia às partes litigantes para trilharem o caminho para pacificação do conflito e tendem a aumentar a possibilidade de as partes manterem uma relação harmônica mesmo após o surgimento do conflito.

\title{
4 MEDIAÇÃO E CONCILIAÇÃO
}

A mediação pode ser entendida, sob o olhar de Warat da seguinte forma:

\begin{abstract}
um processo de reconstrução simbólica do conflito, no qual as partes têm a oportunidade de resolver suas diferenças reinterpretando, no simbólico, o conflito com o auxílio de um mediador, que as ajuda, com sua escuta, interpretação e mecanismos de transferência, para que elas encontrem os caminhos de resolução, sem que o mediador participe da resolução ou influa em decisões ou mudanças de atitude (nisso se baseia sua imparcialidade; é imparcial porque não resolve nem decide). (1998, p. 31)
\end{abstract}

A mediação é uma forma autônoma de pacificação de conflitos, em que um terceiro imparcial, sem poder de decisão, auxilia as partes a reestabelecerem o diálogo a fim de preservar o interesse de ambas, visando o estabelecimento de um acordo benéfico a todos.

Nela as partes possuem plena autonomia, sendo que o mediador não decide nem determina a decisão das partes, apenas ajuda na identificação e articulação das questões essenciais que devem ser resolvidas durante o processo, não influenciando no resultado final.

Diante disso, fica claro que o mediador não julga, nem tampouco compõe o litígio. Ele apenas estimula as partes a chegarem a um acordo.

De acordo com Juan Carlos Vezzulla: imposições de sentenças ou de laudos e com um profissional devidamente 
formado, auxilia as partes a acharem seus verdadeiros interesses e a preserválos num acordo criativo em que as duas partes ganhem. (1998, p. 16) .

A mediação prima pela pacificação dos conflitos, cedendo autonomia às partes que possuem voz ativa para dirimirem as contendas, buscando por elas próprias caminhos e alternativas para pacificação do conflito. É nesse sentido que Medina diz que:

\begin{abstract}
A mediação busca, essencialmente, a aproximação das partes. $\mathrm{O}$ instituto da mediação não se preocupa unicamente com a obtenção de um simples acordo entre os indivíduos litigantes. $\mathrm{O}$ objetivo maior a ser alcançado é o reatamento entre aqueles que estavam em conflito. Pacificar relações, eis o fim máximo pretendido com a mediação. (2004, p. 58-59).
\end{abstract}

A utilização da mediação permite ainda encarar o conflito de forma positiva, extraindo dele seu potencial construtivo e dinamizador das relações sociais. Esse olhar do conflito permite aos confrontantes vislumbrar caminhos para reestabelecer o diálogo e aprimorar a convivência pós-conflito (BRAGA NETO, 1999).

Portanto, a preocupação central da mediação não é pôr termo ao conflito, mas sim proporcionar uma mudança de perspectiva e de atitude de modo a alcançar sua pacificação, através de técnicas que auxiliam a comunicação construtiva e interativa.

No que tange à conciliação, nela há um terceiro imparcial que, de forma diversa da mediação, tem um papel mais ativo, propositivo e intervencional, fazendo sugestões que auxiliem as partes envolvidas a buscarem a pacificação do litígio, podendo ainda indicar caminhos e ponderar soluções para que se chegue à pacificação do conflito.

O CPC de 1973 já admitia a conciliação judicial ou extrajudicial, estimulando-a. Observe-se, por exemplo, que o art. 125 do CPC de 1973 previa, entre as incumbências da autoridade judicial, "tentar, a qualquer tempo, conciliar as partes".

A conciliação extrajudicial depende tão somente da vontade das partes e pode ser feita a qualquer tempo. Ao passo que a conciliação judicial se subdivide em facultativa e obrigatória. Na facultativa, as partes tomam a iniciativa, já na obrigatória, a iniciativa é dever do juiz. Neste sentido, o CPC de 1973 atribuia o caráter de título executivo judicial tanto à "sentença homologatória de conciliação ou de transação, ainda que inclua matéria não posta em juízo" (artigo 475-N, III), quanto ao "acordo extrajudicial, de qualquer natureza, homologado judicialmente" (art. 475-N, V). O Código de 2015 conserva o caráter de título executivo judicial a estes dois instrumentos (artigo 515, II e III).

A conciliação mostra-se como um meio de pacificação de conflitos, no qual os conflitantes procuram sanar as divergências com a ajuda do conciliador. Este 
conciliador deve ser um terceiro imparcial, que aproxime as partes promovendo as negociações, sugerindo e formulando propostas, apontando vantagens e desvantagens, objetivando sempre a resolução do conflito, por meio de um acordo. O conciliador tem ainda poder de sugerir um possível acordo, após uma criteriosa avaliação das vantagens e das desvantagens que tal proposição trará às partes.

Diferencia-se, pois, a conciliação da mediação pelo fato de que na primeira o terceiro interventor tem função mais ativa e prepositiva, podendo, inclusive, indicar possíveis caminhos para pacificar o conflito, o que diversamente não cabe ao mediador.

\section{A AUTOCOMPOSIÇÃO NO NOVO CÓDIGO DE PROCESSO CIVIL}

O Novo Código de Processo Civil traz como um de seus institutos norteadores os meios alternativos de pacificação de conflitos. A opção por estas técnicas vem elencada já no artigo $3^{\circ}, \S 3^{\circ}$, que, diversamente do $\mathrm{CPC} / 73$, estende a incumbência de estímulo aos métodos de pacificação consensual de conflitos aos demais personagens do processo judicial - advogados, defensores públicos e membros do Ministério Público - mesmo nas instâncias extrajudiciais.

Mais adiante, o legislador traz título (Título V) e capítulo (Capítulo V) exclusivos para tratar da mediação e conciliação no processo. O Título $\mathrm{V}$ trata dos mediadores e conciliadores e seus regramentos. Já o Capítulo V traz o artigo 334 e parágrafos que descreve como se dará a sessão de mediação ou conciliação. Em síntese, o autor ao propor a demanda deverá indicar na petição inicial se deseja participar de sessão de mediação ou conciliação. Ato contínuo, preenchido todos os requisitos essenciais e não sendo o caso de improcedência liminar do pedido, o juiz, nas ações de rito comum (modelo procedimental que substituiu os ritos ordinário e sumário), designará audiência de conciliação ou de mediação com antecedência mínima de 30 (trinta) dias, devendo ser citado o réu com pelo menos 20 (vinte) dias de antecedência. A parte que não comparecer à audiência sem justificativa plausível será condenada a multa de até $2 \%$ (dois por cento) da vantagem econômica pretendida ou do valor da causa, revertida em favor da União ou do Estado (art. 334, §8) ${ }^{3}$.

\footnotetext{
${ }^{3}$ Art. 334. Se a petição inicial preencher os requisitos essenciais e não for o caso de improcedência liminar do pedido, o juiz designará audiência de conciliação ou de mediação com antecedência mínima de 30 (trinta) dias, devendo ser citado o réu com pelo menos 20 (vinte) dias de antecedência. $[\ldots]$
} 
Outra questão que merece destaque é que o Código traz a compreensão de que, por vezes, uma única sessão de mediação ou conciliação não é suficiente para pacificar o conflito. Quando as partes e o mediador/conciliador entenderem pela possibilidade de se chegar a um consenso e que se faz necessário outro(s) encontro(s), poderão marcar data para nova sessão, desde que não exceda a dois meses da data da primeira sessão $\left(\operatorname{art} .334, \S 2^{\circ}\right)^{4}$.

O segundo ponto, que em muito se relaciona com o primeiro, é que, visando evitar o que hoje ocorre muito comumente nas audiências de conciliação dos Juizados Especiais Estaduais, por exemplo, impõe o novo Código que a pauta de audiência será organizada com, pelo menos, 20 (vinte) minutos de diferença entre uma sessão e outra (art. 334, §12) $)^{5}$. Assim, o legislador traz mecanismos para evitar sessões "condenadas ao fracasso".

Um terceiro ponto e não menos importante, é o que traz o artigo $165^{6}$ do novo Código Processual, que supera uma das críticas sobre as audiências "judicializadas" de conciliação. Isso porque, de acordo com o novo diploma legal, estas sessões acontecerão nos Centros Judiciários de solução consensual de conflitos. O modelo anterior (do CPC/73) mostrava-se impotente diante da realidade, nele haveria uma "pausa" no processo adversarial, para então se iniciar uma relação harmônica e consensual. Nesse momento esperava-se que o juiz se dispa de sua autoridade e, simultaneamente às partes em conflito (que saem da condição de figurante e passam a condição de protagonistas) e seus representantes legais, se desarmem e agora, em pé de igualdade, tentem encontrar uma solução que atenda aos interesses das partes litigantes dentro do espaço frio e angustiante que é a sala de audiência (REBOUÇAS, 2012).

Outra questão interessante é a vedação expressa de utilização de qualquer meio de coerção para que as partes aceitem o acordo proposto. A parte final do $\S 2^{\circ}$ do art.

$\S 8^{\circ} \mathrm{O}$ não comparecimento injustificado do autor ou do réu à audiência de conciliação é considerado ato atentatório à dignidade da justiça e será sancionado com multa de até dois por cento da vantagem econômica pretendida ou do valor da causa, revertida em favor da União ou do Estado.

${ }^{4}$ Art. 334 Omissis

[…]

$\S 2^{\circ}$ Poderá haver mais de uma sessão destinada à conciliação e à mediação, não podendo exceder a 2 (dois) meses da data de realização da primeira sessão, desde que necessárias à composição das partes.

${ }^{5}$ Art. 334. Omissis

[…]

$\S 12$. A pauta das audiências de conciliação ou de mediação será organizada de modo a respeitar o intervalo mínimo de 20 (vinte) minutos entre o início de uma e o início da seguinte.

${ }^{6}$ Art. 165. Os tribunais criarão centros judiciários de solução consensual de conflitos, responsáveis pela realização de sessões e audiências de conciliação e mediação e pelo desenvolvimento de programas destinados a auxiliar, orientar e estimular a autocomposição. 
165 indica que é "vedada a utilização de qualquer tipo de constrangimento ou intimidação para que as partes conciliem”. Não raras são as vezes que o conciliador judicial se utiliza de meios de pressão para fazer com que as partes aceitem algum acordo. Ainda mais grave é a distorção do papel dos juízes que, para “agilizar” o seu próprio serviço, pressionam as partes afirmando expressamente (ou quase) a uma dos conflitantes que ele deveria aceitar uma certa proposta, pois o acordo the seria mais vantajoso que a decisão por ele proferida. O mais grave é que essa supressão de autonomia é revestida por um discurso de garantia da própria liberdade das partes. (COSTA, 2004)

A prática de tais condutas ofende toda a principiologia que permeia os meios de pacificação de conflitos, em especial a boa-fé e a autonomia de vontade. Portanto o modelo apresentado pelo CPC/15 visa, ao menos em tese, evitar que as práticas de mediação e conciliação não se resumam a uma imposição de acordo, perdendo seu caráter dialógico e se deslegitimando como sistema autocompositivo. Prevê-se, inclusive, que, caso o mediador ou conciliador não obedeça esta regra, poderá ser excluído do cadastro de conciliadores e mediadores, na forma do art, $173, \S 1^{\circ}$ :

Art. 173. Será excluído do cadastro de conciliadores e mediadores aquele que: I - agir com dolo ou culpa na condução da conciliação ou da mediação sob sua responsabilidade ou violar qualquer dos deveres decorrentes do art. 166, $\S \S 1^{\circ}$ e $2^{\circ}$;

Outra interessante abordagem que traz o CPC/15 é sobre a importância da autocomposição nos conflitos familiares, determinando o artigo 694, caput, que "nas ações de família, todos os esforços serão empreendidos para a solução consensual da controvérsia, devendo o juiz dispor do auxílio de profissionais de outras áreas de conhecimento para a mediação e conciliação".

Esta previsão legal mostra-se como uma importante iniciativa, já que é essencial dispor de meios para que os membros da família possam, por eles próprios, enfrentarem e superarem seus conflitos sem precisar delegar seu protagonismo a terceiros (TARTUCE, 2015).

As controvérsias familiares envolvem pessoas ligadas por fortes laços de afetividade e sentimentos muito íntimos oriundos de um histórico prévio de conflitos, que em regra não são solucionados por uma decisão judicial imposta por um terceiro que desconsidera todos os sentimentos ali envolvidos e decide sobre uma tese jurídica.

Há ainda nos processos de família previsão de determinadas cautelas que deverão ser adotadas quando do recebimento da petição inicial e da expedição do 
mandado de citação, demonstrando-se certa sensibilidade com as questões do direito de família e a preocupação de que a solução, nesses casos, seja realmente construída pelas próprias partes, de modo a propiciar a preservação de uma relação entre os envolvidos, importante e necessária nessas situações.

Por outro lado, é preciso tecer algumas reflexões sobre importantes questões que podem comprometer a eficácia desta nova proposta do Código processual. Um destes pontos é a obrigatoriedade da sessão de conciliação e mediação mesmo que uma das partes declare expressamente seu desinteresse ${ }^{7}$. Adolfo Braga Neto há muito já indicava não ser possível mediar ou conciliar quando houver "o interesse de uma das partes em manter a litigiosidade na relação e com isso não predispor da negociação na tentativa de solucionar seus conflitos” (BRAGA NETO, 1999, p. 96). Suscitando e adaptando o jargão popular, onde um não quer, dois não conciliam.

Fernando da Fonseca Garjadoni, falando sobre essa obrigatoriedade da mediação ou conciliação pontua uma série de possíveis problemas a serem enfrentados:

\begin{abstract}
A opção traz problemas práticos concretos: a) quebra-se aquilo que de mais caro há nos métodos consensuais de solução de conflito, a autonomia da vontade, lançada pelo próprio legislador como princípio da mediação (art. 166 CPC/2015); b) burocratiza-se a mediação/conciliação, obrigando todas as partes, mesmo não querendo, a se submeter a ela, simplesmente porque uma delas deseja; e c) dá azo a manobras processuais protelatórias, com um dos demandados aceitando a audiência, apenas, para ganhar mais alguns meses de tramitação processual, sem possiblidade de intervenção judicial para obstar a manobra; e d) torna maior o custo do processo, pois além do pagamento pelos serviços do mediador/conciliador, o demandado domiciliado em outra localidade, praticamente em todas as ações, deverá se deslocar para a audiência de mediação/conciliação no foro da propositura. (2015).
\end{abstract}

Essa obrigatoriedade parece não se adequar a real essência dos meios autônomos de pacificação de conflitos, porque as partes perdem a autonomia de sua vontade e são obrigadas a participarem da sessão de mediação/conciliação mesmo declarando expressamente não ter interesse (bastando apenas que a parte contrária se manifeste favoravelmente).

\footnotetext{
${ }^{77}$ Art. 334 Omissis

[...]

$\S 4^{\circ}$ A audiência não será realizada:

I - se ambas as partes manifestarem, expressamente, desinteresse na composição consensual;

II - quando não se admitir a autocomposição.

$\S 5^{\circ} \mathrm{O}$ autor deverá indicar, na petição inicial, seu desinteresse na autocomposição, e o réu deverá fazê-lo, por petição, apresentada com 10 (dez) dias de antecedência, contados da data da audiência.

$\S 6^{\circ}$ Havendo litisconsórcio, o desinteresse na realização da audiência deve ser manifestado por todos os litisconsortes.
} 
Há, ainda, que se pensar no custo financeiro e na qualidade da mediação/conciliação, isso porque o novo Código estabelece que:

\begin{abstract}
Art. 169. Ressalvada a hipótese do art. $167, \S 6^{08}$, o conciliador e o mediador receberão pelo seu trabalho remuneração prevista em tabela fixada pelo tribunal, conforme parâmetros estabelecidos pelo Conselho Nacional de Justiça.

$\S 1^{\circ} \mathrm{A}$ mediação e a conciliação podem ser realizadas como trabalho voluntário, observada a legislação pertinente e a regulamentação do tribunal. $\S 2^{\circ}$ Os tribunais determinarão o percentual de audiências não remuneradas que deverão ser suportadas pelas câmaras privadas de conciliação e mediação, com o fim de atender aos processos em que deferida gratuidade da justiça, como contrapartida de seu credenciamento.
\end{abstract}

Da leitura do dispositivo legal, se percebe que, ressalvadas as hipóteses de se tratar de mediadores e conciliadores investidos em cargo público, os demais receberão "por produtividade" conforme tabela previamente fixada pelo tribunal. E, em casos de beneficiários da gratuidade da justiça, os centros privados realizarão a sessão de mediação ou conciliação gratuitamente, dentro de um percentual estabelecido pelos tribunais, em contraprestação ao seu credenciamento.

Assim, é importante que os Tribunais estejam atentos para que as sessões de conciliação e mediação não se tornem fonte de lucro indiscriminado, relegando-se a qualidade do trabalho dos mediadores e conciliadores.

É necessário também que os Tribunais equipem as comarcas com a criação de centros de mediação/conciliação, para esquivarem-se do ambiente angustiante e adversarial dos Fóruns (Cárcova, 1988) e evitar que se repitam as experiências frustrantes que costumavam ocorrer na vigência do Código de 1973. Faz-se igualmente necessário a contratação e formação de mediadores/conciliadores até que se tenha um corpo profissional suficiente e preparado para atender as demandas em um razoável espaço de tempo, evitando que as sessões sejam marcadas para datas muito distantes e tornem todo o processo ainda mais moroso (perdendo, inclusive, a aclamada celeridade processual que visa o novo Código).

A respeito disso é importante também ponderar quão urgente é a capacitação dos mediadores e conciliadores, demandando um constate aprimoramento, seja das técnicas aplicáveis a esses mecanismos, seja da sensibilidade inerente às percepções de

\footnotetext{
${ }^{8}$ Art. 167. Os conciliadores, os mediadores e as câmaras privadas de conciliação e mediação serão inscritos em cadastro nacional e em cadastro de tribunal de justiça ou de tribunal regional federal, que manterá registro de profissionais habilitados, com indicação de sua área profissional.

$\S 6^{\circ} \mathrm{O}$ tribunal poderá optar pela criação de quadro próprio de conciliadores e mediadores, a ser preenchido por concurso público de provas e títulos, observadas as disposições deste Capítulo.
} 
cada conflito. Sem o devido preparo, a abertura conferida pelo CPC/15 pode resultar, de modo contraditório, no enfraquecimento da autocomposição de conflitos.

Por fim, merece destaque a obrigatoriedade da presença do advogado ou defensor nas sessões de mediação e conciliação, consoante lição do artigo 334 , $\S 9^{\circ}$ e $10^{\circ}$ :

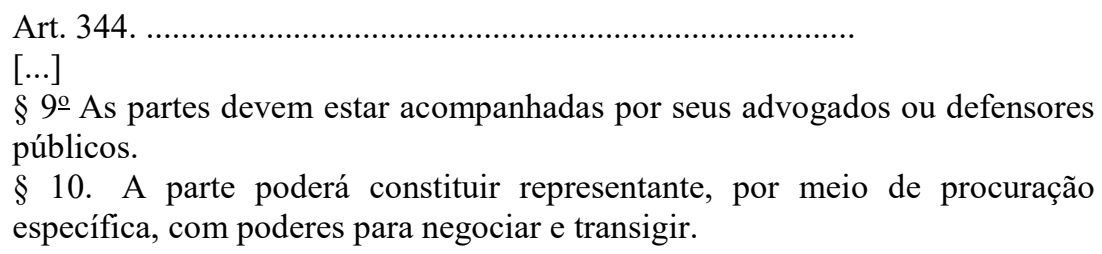

Este é outro ponto em que o novo Código se distancia da real ideia de mediação e conciliação, porque as partes continuam sendo representados por um terceiro que relatam por elas seus dilemas e deixam de construírem de forma autônoma os caminhos para pacificar o conflito.

A autonomia da vontade, imprescindível na mediação e na conciliação, é compreendida como o dever de respeitar os diferentes pontos de vista dos envolvidos, garantindo-lhes que cheguem a uma decisão voluntária e não coercitiva, construída conforme suas necessidades e desejos.

Esta imposição parece ser um apego à forma adversarial de lidar com os conflitos, não permitindo que as partes sejam, efetivamente, protagonistas de seus próprios dilemas e construam por elas mesmas o caminho para pacificar o conflito.

Em síntese, percebe-se que o legislador concedeu especial atenção à autocomposição de conflitos, primando pela ideia do reestabelecimento do diálogo e extração do potencial construtivo do conflito e pela busca de caminhos que retomem a relação harmoniosa anterior. O grande desafio, no entanto, será a verdadeira concretização de tais promessas, especialmente por meio da adequada preparação dos atores e dos recursos reais para sua implementação.

\section{CONCLUSÃO}

Os meios alternativos de pacificação de conflitos têm destaque por valorizarem o reestabelecimento do diálogo e por rejeitarem a ideia de vencedor e vencido. O Novo Código de Processo Civil disciplina, em geral de forma positiva, a aplicação de tais meios e se constitui grande marco no caminho do acesso à justiça. 
Espera-se que a médio prazo ocorra o amadurecimento destas técnicas e sua ampla utilização, abandonando-se a atual postura de litigância desmedida, antes mesmo da tentativa de diálogo com a parte contrária.

Para que isto seja possível será necessário que os magistrados, os advogados, defensores públicos, membros do Ministério Público, serventuários da Justiça e todos os demais profissionais do direito reconheçam a importância dos mecanismos consensuais e cedam espaço para que as partes dialoguem e busquem conjuntamente o entendimento.

As inovações legislativas representam um passo importante, mas a caminhada dependerá, sobretudo, da mudança cultural da forma de encarar e conflito e buscar soluções.

Mediação e conciliação, assim, apresentam-se como meios promissores ao acesso à justiça, sendo essencial a devida compreensão de seu caráter emancipatório, e sua efetiva e correspondente utilização, de modo a garantir que a perspectiva inovadora do novo CPC brasileiro possa se concretizar verdadeiramente.

\title{
MEDIATION AND CONCILIATION: reflections under the light of the new Civil Procedure Code
}

\begin{abstract}
This paper make reflections about mediation and conciliation according to the New Civil Procedure Code, which entered into force in March 2016. It analyzes the inability of the Judiciary Power solving people real problems, besides demonstrating that one of the paths to overcome this obstacle is using alternative ways of pacification of conflicts. On these autonomous ways of conflicts composition the parts have active voice and they are the protagonists of decisions. It will be analyzed here the mediation and conciliation institutions and how they are treated in the new procedural law, outlining some positive considerations and others that indicate the necessity of reflection on the new legal provisions usefulness and effectiveness.
\end{abstract}

Keywords: Mediation. Conciliation. New Civil Procedure Code.

\section{REFERÊNCIAS}

BAStOS, Simone de A. R. A Análise do Conflito. Apostila do Curso de Resolução de Conflitos para Representantes de Empresas. ENAM, 2014. 
BEZERRA, Tássio. A mediação enquanto instrumento de emancipação da cidadania e de democratização da justiça e do direito. Revista Direito e Sensibilidade, $1^{\mathrm{a}}$ ed., v. 1 , n ${ }^{\mathrm{o}} 1$, 193-210, 2011.

BRAGA NETO, Adolfo. Os Advogados, os Conflitos e a Mediação. In: OLIVEIRA, Ângela (org). Métodos de Resolução de Controvérsias. São Paulo: LTr, 1999.

BRASIL, Lei Federal $n^{\circ} 13.105$, de 16 de março de 2015. Institui o Novo Código de Processo Civil. Brasil, Brasil. Disponível em: $<$ http://www.planalto.gov.br/ccivil_03/_ato2015-2018/2015/lei/113105.htm>. Acesso em: 12 de fev. 2016.

CAPPELLETTI, Mauro; GARTH, Bryant. Acesso à Justiça. Tradução Ellen Gracie. Northfleet. Porto Alegre: Fabris, 1988.

CAPPELLETTI, Mauro. Os métodos alternativos de solução de conflitos no quadro do movimento universal de Acesso à Justiça. Revista do Processo. São Paulo: RT, nº 74 , ano 19, p. 82-97, abril-junho/1994.

CÁRCOVA, Carlos María. A Opacidade do Direito. Tradução de Edilson Alkmim Cunha. São Paulo: LTr, 1998.

COSTA, Alexandre Araújo. Cartografia dos métodos de composição de conflitos. In: AZEVEDO, André Gomma (org). Estudos em arbitragem, mediação e negociação. v. 3, Brasília: Grupo de Pesquisa, 2004.

GAJARDONI, Fernando da Fonseca. Novo CPC: Vale apostar na conciliação/mediação?. Disponível em: $<$ http://jota.info/novocpcvaleapostarnaconciliacaomediacao>. Acesso em: 05 mai. 2015. MEDINA, Eduardo Borges de Mattos. Meios Alternativos de Solução de Conflitos. Porto Alegre: Sérgio Antonio Fabris Editor, 2004.

REBOUÇAS, Gabriela Maia. Tramas entre subjetividades e direito: A constituição do sujeito em Michel Foucault e os sistemas de resolução de conflitos. Rio de Janeiro: Lumen Juris, 2012.

SIVIERO, Karime Silva. Aspectos Polêmicos da Mediação Judicial Brasileira: Uma Análise à Luz do Novo Código de Processo Civil e da Lei da Mediação. Cadernos de Pós Graduação Direito UFRGS. Volume 10, nº 3, p. 316-316, 2015.

TARTUCE, Fernanda. Mediação no Novo CPC: questionamentos reflexivos. Disponível em: <http://www.fernandatartuce.com.br/site/aulas/doc_view/339-mediacao-no-novocpc-tartuce.html>. Acesso em 07 fev. 2016.

Mediação de conflitos, inclusão social e linguagem jurídica: potencialidades e superações. Disponível em $<$ http://www.fernandatartuce.com.br/wpcontent/uploads/2016/01/Media\%C3\%A7\%C3\%A3o-linguagem-e-inclus\%C3\%A3oBortolai -e-Tartuce.pdf $>$. Acesso em 07 fev. 2016. 
TRENTIN, Taise Rabelo Dutra; TRENTIN Sandro Seixas. A Mediação e a Conciliação Previstas no Novo Código de Processo Civil: Democratizando o Acesso à Justiça. XXII Encontro Nacional do CONPEDI/UNINOVE p. 97-112, Disponível em $<$ http://www.publicadireito.com.br/publicação/uninove/livro.php?gt=197>. Acesso em 05 mai. 2015.

VEZZULA, Juan Carlos. Teoria e Prática da Mediação. Curitiba: IMAB, 1998.

WARAT, Luis Alberto. Em nome do acordo: a mediação no direito. Buenos Aires: Angra Impresiones, 1998. 